\title{
From the shelves and into the world Imagining information literacy in the everyday
}

W

hen I was the instruction librarian at York College of Pennsylvania, I hosted From the Shelves, a show on WVYC, the campus radio station. Outside of teaching, it was my favorite part of the job. I played music spanning genres and artists: the Mountain Goats, Petula Clark, XTC, De La Soul, and Katy Perry. Part of the fun was planning themed editions: two hours of music built around a central idea (e.g., foreignlanguage versions of popular songs, songs featuring spelling, and songs containing cowbell).

In 2012, I decided to play two hours of music illustrating aspects of information literacy (IL). Building the playlist opened my eyes to how much I had defined IL's meaning and value of library-related research projects and traditional scholarship. Building the playlist encouraged me to imagine how IL's central skills and concepts play out in every aspect of our lives: academic, professional, and personal.

Before I illustrate this with Taylor Swift's "Shake It Off," some background on building the playlist. On my own, I came up with a limited number of songs. Googling "library songs" yielded results. Googling "information literacy songs" did not. So, I appealed to the collective wisdom of the ALA's information literacy listserv, ILI-L. Within weeks, I received dozens of suggestions, and compiled a playlist, arranging everything into three categories. ${ }^{1}$

The organization of the first two, songs about the research experience and songs about libraries/ librarians/reading, was obvious. Organizing the third, however, songs describing elements of IL as described the Information Literacy Competency
Standards for Higher Education (the guiding document of the time), wasn't so straightforward.

The standards present IL as a set of discrete, predictable, and generic skills, ${ }^{2}$ but that's not how most songs describe them. They place those skills in the context of some lived experience, not a research assignment. Take Don Henley's "Dirty Laundry." Told from the perspective of a news anchor, it functions as a broad critique of the media. From the perspective of the standards, it could fit under Standard One (the news a source of information), Standard Three (the critical evaluated of sources), and Standard Five (issues surrounding information use). Similar examples, like Stan Freeberg's "Tele-Vee-Shun" and the Disposable Heroes of Hiphoprisy's "Television, the Drug of the Nation," were equally complex and defied easy classification. A skill-based classification seemed inadequate for developing a nuanced understanding of the complexity of any lived experiences of IL.

So, when the Framework for Information Literacy for Higher Education came along and offered a way for understanding IL as social practice, I was intrigued by the possibility of using its frames-Scholarship as a Conversation, Research as Inquiry, Searching as Strategic Exploration, Authority is Constructed and Contextual, Information Creation as a Process, and Information has Value- to guide an understanding of how IL

Joel M. Burkholder is reference and instruction librarian at Penn State York's Lee R. Glatfelter Library, email: jmb7609@psu.edu

(C) 2021 Joel M. Burkholder 
is experienced in context. And the playlist gave me plenty of material to analyze.

Now, let's look at "Shake It Off." At first listen, it seems like just another entry in Swift's impressive catalog of hits. Yet, that trivializes what it says about the constructed and contextual nature of authority. In the first verse, she sings:

I stay out too late

Got nothing in my brain

That's what people say, $\mathrm{mmm}-\mathrm{mmm}$

That's what people say, $\mathrm{mmm}-\mathrm{mmm}$

I go on too many dates

But I can't make 'em stay

At least that's what people say, $\mathrm{mmm}-\mathrm{mmm}$

That's what people say, $\mathrm{mmm}-\mathrm{mmm}^{3}$

For much of her career, a narrative of her as a vapid wild-child and a high-maintenance maneater has been a fixture of the entertainment media. Turn on Access Hollywood. Read US Weekly. Visit $T M Z$. Though not scholarly, it's a conversation taking place in a variety of venues with varying information creation processes. And while some may question the accuracy of certain claims or the credibility of certain authors, the pervasiveness of the narrative grants it a widely recognized authority.

Like a public relations offensive, verse two attempts to co-opt the narrative. She asserts her personal authority and presents a different picture:

I never miss a beat

I'm lightning on my feet

And that's what they don't see, $\mathrm{mmm}-\mathrm{mmm}$

That's what they don't see, $\mathrm{mmm}$-mmm

I'm dancing on my own

I'll make the moves up as I go

And that's what they don't know mmm-mmm

That's what they don't know mmm-mmm ${ }^{4}$

Does it correct any misconceptions? If you're a fan, maybe. But that may be beside the point. She recognizes the dominant authority of the sensational story. The only option is to "shake it off." In a commentary about the song, Swift says:

You know the feeling of humiliation is the same when a girl has a rumor spread around about her at school that isn't true. It's the same feeling I feel when I'm checking out at the grocery store, and I read some crazy headline about me. And I think the way we have to deal with those issues is the same-you have to learn to have a sense of humor about things after a while or else you'll just live in an endless sea of resentment and bitterness. ${ }^{5}$

Swift has admitted, however, that resisting the narrative's authority is easier said than done. ${ }^{6}$ For her, dealing with the constructed and contextual nature of authority is more than an academic exercise, it has real impact on her life. Understanding that perspective helps reveal the ways this concept of the Framework is embedded in the artifacts of culture, not just academia.

I'm not suggesting librarians analyze songs (or novels, advertisements, and movies) for the sole purpose of identifying captivating examples to use in the classroom. Teaching students to identify IL's presence in the everyday creates an awareness of skills and concepts beyond the limits of a student's academic career. And for librarians, it can foster a more holistic view of what we teach. If it is a context-specific social practice, then we need to understand those contexts as they are experienced. If Taylor Swift, Talking Heads, or Tool can show us the way, why don't we see where they can take us?

\section{Notes}

1. Joel M. Burkholder, "Information Literacy Playlist," April 30, 2020, https://sites.psu.edu /infolitplaylist/.

2. Nancy M. Foasberg, "From Standards to Frameworks for IL: How the ACRL Framework Addresses Critiques of the Standards," portal: Libraries and the Academy 15, no. 4 (2018): 699717. https://doi.org/doi:10.1353/pla.2015.0045.

3. Nina Braca, "Here Are the Lyrics to Taylor Swift's 'Shake It Off,'” Spin online, May 22, 2019. https://www.spin.com/2019/05/taylor-swift -shake-it-off-lyrics/.

4. Ibid.

5. Taylor Swift, "Shake It Off (Commentary)," YouTube video, 2018, https://youtu. be/zN6bRuXOkD8.

6. Laura Snapes, “Taylor Swift: 'I Was Literally about to Break': The Singer Spills on Feuds, Fame, Failure-and Why She's Taking on Trump," The Guardian, August 24, 2019, https://www. theguardian.com/music/2019/aug/24/taylor -swift-pop-music-hunger-games-gladiators. 2 